\title{
What about the "Social Aspect of COVID"? Exploring the Determinants of Social Isolation on the Greek Population during the COVID-19 Lockdown
}

\author{
Evgenia Anastasiou *(D) and Marie-Noelle Duquenne \\ Department of Planning and Regional Developmen, University of Thessaly, Pedion Areos, 38334 Volos, Greece; \\ mdyken@uth.gr \\ * Correspondence: evanastasiou@uth.gr
}

Citation: Anastasiou, Evgenia, and Marie-Noelle Duquenne. 2021. What about the "Social Aspect of COVID"? Exploring the Determinants of Social Isolation on the Greek Population during the COVID-19 Lockdown. Social Sciences 10: 27. https:// doi.org/10.3390/socsci10010027

Received: 20 December 2020

Accepted: 14 January 2021

Published: 18 January 2021

Publisher's Note: MDPI stays neutral with regard to jurisdictional claims in published maps and institutional affiliations.

Copyright: (c) 2021 by the authors. Licensee MDPI, Basel, Switzerland. This article is an open access article distributed under the terms and conditions of the Creative Commons Attribution (CC BY) license (https:// creativecommons.org/licenses/by/ $4.0 /)$.

\begin{abstract}
The COVID-19 pandemic, its duration, and its intensity are harbingers of demographic change. In the context of social demography, it is crucial to explore the social challenge emerging from the coronavirus disease. The main purpose of this study is (i) to explore the determinants that affected the population in Greece in terms of social isolation during the lockdown period and (ii) to examine possible differences in the assessment of the social isolation factors depending on whether individuals live in urban or rural areas or regions with relative geographical isolation. Field research was conducted with 4216 questionnaires during the first wave of COVID-19 (March to April 2020). Multivariate analysis methods were applied to detect the main factors that impacted the feeling of social isolation, and nonparametric tests were performed to detect possible differences between population groups. Despite the resistance shown to the spread of the disease, the Greek population totally complied with the measures of social distancing and thus was socially and psychologically affected. The results indicate that psychosomatic disorders, employment situations, changes in sleep habits, socialization on the Internet, demographic status, health concerns, and trust in government and the media response determine the Greeks' social isolation feeling. Pandemic and confinement measures have consequences for individuals and social groups and may prejudice social cohesion at multiple levels. By understanding how the pandemic affected the societies, interventions and public policies may be implemented to ensure both social cohesion and populations' wellbeing by addressing the social isolation feeling.
\end{abstract}

Keywords: COVID-19; lockdown; social demography; population; social isolation; sociodemographic factors; urban-rural areas; Greece

\section{Introduction}

The social consequences of the current COVID-19 pandemic are certainly a very important and pressing avenue for research. The current health crisis posed by COVID19 constitutes a threat not only to the physical integrity of the population but also to mental health and social cohesion. The normality of the Greek population's lives has now changed, and the new, different reality is currently expanding with indefinite evolution and unknown effects on multiple levels. In this new context in which the deregulation of society is observed, the questions raised concern deeper questions at the individual and collective levels for the Greek and international scientific community. At the same time, it is highlighted the need for progress and social cohesion on the basis of individual responsibility and collective consciousness.

In view of this, the social reaction and the impact on people's behavior under the influence of fear and anxiety regarding the pandemic are ambiguous. Consequently, the need to investigate the social impact of COVID-19 is considered both mature and imperative, especially after the implementation of restrictive social distancing measures. The initial aim of the present research is to highlight to what extent the distancing measures 
and house confinement have actually affected and maybe strengthened the feeling of social isolation of the Greek population. The first research question that arises, therefore, is the following: what are the main factors that impacted this feeling during the very strict confinement imposed from 14 March until 4 May 2020, when the country gradually began to lift certain restrictive measures, especially as regards population movements? A better understanding of this phenomenon is essential since the evolution of the pandemic remains very uncertain, and therefore it is quite possible that containment measures-at least locally-will be once again imposed.

The present study consists of four sections. First, a short literature review presents the situation in Greece posed by the pandemic, and also reference is made to the main causes of social isolation feeling and its impact on the population in Greece. The Data and Methods section follows, where the authors introduce their online survey (4238 questionnaires) and the proposed methodology to explore the determinants of social isolation on the Greek population. In the third section, there are presented the results of the analysis, and finally, the study ends with the Conclusions, where the main findings are discussed.

\section{Literature Review}

\subsection{The Chronicle of COVID-19 in Greece}

The first case of the coronavirus in Greece was announced at the end of February 2020, marking the beginning of a series of developments. On 10 March, the Greek government announced the closure of kindergartens, schools, universities, and tuition centers across the country (O.J. 2020a). Further preventive actions concerned the significant reduction or suspension of most economic and social activities. Shortly afterward (14 March), the closure of shopping malls, shops, cafes, bars, restaurants, museums, cinemas, touristic accommodation entered into force (O.J. 2020c), while emergency measures were applied in supermarkets (16 March). At the same time, the cultural events were postponed or delayed, and public open spaces, parks, and places of worship closed over the pandemic fear. As regards public open spaces and their use (Anastasiou and Manika 2020), social distancing may highlight changes in peoples' perceptions as new needs emerge. These actions contributed to slowing down the spread of the disease, reducing the pressure on health services, and allowing the care system to provide better care.

Uncertainties regarding the behavior of the coronavirus, though, created an anxious situation in the local and global community. Considering that a country is not able to face, without consequences, external risks of this magnitude, further important containment measures to tackle COVID-19 were adopted in Greece, as worldwide. The new reality came into force on 23 March as a logical continuation of the course of the virus in Greece, that is, the lockdown. The state directives concerned the restriction of the physical, social activity of the citizens, and in specific cases, instead of social distancing, mandatory quarantine was required (European Union Agency for Fundamental Rights (FRA) 2020). The lockdown in Greece (O.J. 2020b) lasted 42 days (23 March to 4 May). During this period, an exceptional mobility management service was designed and launched, with the OECD designating it as best practice (OECD 2020a). The permissible reasons for exceptional mobility concern (i) going to a pharmacy or visiting a doctor, (ii) going to a goods supply store, (iii) going to the bank, in case an electronic transaction is not possible (iv) movement to help people in need (v) going to a ceremony, under the conditions provided by law or communication between divorced/separated parents and children, in accordance with the provisions (vi) outdoor physical exercise or walk with a pet. During the lockdown period, more than 110 million text messages for exceptional mobility were processed. The vast majority of Greeks state that they complied with the restrictive measures (Anastasiou and Duquenne 2020). However, many used the service of exceptional mobility and left their home more than once per day (Georgakopoulos 2020). Apart from the overall lockdown implemented in Greece, the Greek government imposed a mandatory quarantine in certain areas and/or communities that experienced particularly high levels of COVID-19 spread. 
During the lockdown in Greece, apart from social, economic activity also came to a standstill. More specifically, about half of the economic activity in the country has stopped: of those who worked, one in four worked normally, one in four deployed teleworking (Eurofound 2020), and the rest either worked part-time or were suspended (Georgakopoulos 2020). The response of the private sector on teleworking establishment was immediate, and the employees appear positive to move to a different work model (KPMG 2020; Ragazou 2020).

\subsection{Impact of COVID-19 on Social Isolation Demography}

The health data of Greece on COVID-19 show that the spread of the virus and consequently the loss of human life are limited (NPHO 2020; Panagiotopoulos and Papamichail 2020), which indirectly reflects the significance of the timely and correct implementation of the social distancing measures. However, the social standards and values supporting free movement must be weighed on the basis of risk acceptance on the part of the population (AAICJ 1985). The path between social distancing and social isolation is short, and such horizontal policy measures need to agree in principle with respect for human and social rights but also count the significant public reaction. Recent research on determinants of population-based strategies for health protection supports the importance of age, social status, and income (Gutik Valerievna and Gareeva 2020).

The physical distancing measures to prevent medical health may lead to the disruption of social capital, that is, instabilities and disruptions in the life of populations concerned by the measures. The confinement has harsh consequences both individually as concerns mental health and wellbeing (Ammar et al. 2020; Galea et al. 2020) and collectively as regards social cohesion: the new rules of social life have obviously social consequences (UNDP 2020), interfering on the daily life of individuals and families (Nicola et al. 2020) while attitudes and practices are likely to change not only during confinement but also after (UN 2020).

At the individual level, social distancing does not present the same degree of isolation feeling as people and/or certain population groups react differently to the pandemic stressful situation (Qiu et al. 2020; Wang et al. 2020). The social distancing, the abrupt change in the everyday patterns as well as the direct access to the information about the pandemic, is rapidly evolving the fear of the unknown and the feeling of isolation from the outside world. The people's concerns increased also encapsulate economic worries both for the present and the period after. The period of the outbreak bears strong emotions like anxiety, anger, sadness, and overwhelm. Recent research on COVID-19 impact on isolation feelings shows an association with smoking, alcohol abuse, emotional eating, and depression (Douglas et al. 2020).

Due to the pandemic, social isolation-often leading to loneliness feeling-is increasingly seen as major public health and, consequently, social concern (Armitage and Nellums 2020). Various studies based on surveys have shown that social isolation-whatever the causes-generates "significant and long-term negative outcomes" for all ages and especially for the elderly population (Berg-Weger and Morley 2020). The development of various forms of social support contributes to reducing the negative effects of social isolation since it is considered as its "natural counterpart" (Tomaka et al. 2006). The development of social support should contribute to strengthening social cohesiveness, which, in turn, has positive effects on wellbeing and public health (Stansfeld 2006).

The literature on the feeling of social isolation of the Greek population during the COVID-19 confinement measures is yet limited. Greece has not escaped this brutal crisis and requires obviously swift and appropriate responses. A recent study carried out in Greece (Anastasiou and Duquenne 2020) has indeed highlighted that confinement has greatly enhanced the feeling of social isolation for a significant part of the Greek population (35\%), mainly women, young people under 30 years and those on work's suspension, causing not only psychological discomfort but also fear about the future. Furthermore, research reports a close connection between the quality of working life 
and the psychological state (Manika 2020; Wardani and Anwar 2019), resulting in the above. These first results are consistent with those obtained by other studies carried out in Greece (Georgakopoulos 2020) and also in some other countries having applied coronavirus lockdown measures (UK YOUTH 2020; UN WOMEN 2020). Consequently, it is not surprising that the 1st Eurofound e-survey (Living, working and Covid-19), providing a snapshot of the pandemic on people's lives in the E.U. countries, highlighted that during the 1st lockdown in Greece, the population reported a feeling of low wellbeing (Eurofound 2020). Moreover, this feeling is not perceived in the same way or intensity throughout the population. Sociodemographic characteristics, economic and employment situation, but also the place of residence are all factors contributing to explain that certain population groups are more vulnerable and exposed to loneliness and social isolation.

\section{Data and Methods}

The main purpose of this study is to explore the determinants that affected the population in Greece in terms of social isolation feeling during the first lockdown period. Two questions are therefore examined: (i) through the perception in itself of the survey's participants, what are the main factors which, according to them, can have a significant impact on such a feeling? (ii) is it possible to detect significant differences between specific groups of the population as, for example, urban and rural citizens, or population living in islands or inland areas?

The research initiative exploited the international literature to identify the social effects on populations, arising from the threat of a crisis or the presence of an infectious epidemic or pandemic disease (Barrett et al. 2011; Suárez Fernández 2011). A tool for measuring the attitudes, behavior, and perceptions of the population in relation to the measures of social isolation and house confinement was designed. The present survey, consequently, aimed to map the way Greeks lived, think, and felt during the lockdown. The questionnaire, which was initially assessed for validity and reliability through a pilot survey, consists of four sections: (a) demographic characteristics (b) assessment by the respondents about their general psychosomatic situation during the confinement measures (9 items; $\alpha=0.90$ ). (c) daily attitudes and behaviors before and during confinement (8 items; $\alpha=0.72$ ) (d) population's perceptions about COVID-19 (5 items; $\alpha=0.68$ ).

More specifically, gender, age, marital status, educational status, professional function, and region of residence were collected in the first section of the survey. Regarding the second section, it is foreseen that infectious outbreaks widely impact the general psychosomatic situation of the populations and determine the isolation and loneliness feeling (Gica et al. 2020). Emotional distress, tension and irritability increased during the pandemic compared to the period before (Ismail et al. 2020). Furthermore, the available scientific literature and research data report increased anxiety, pressure, and exhaustion caused by the COVID outbreak (Wielgus et al. 2020).

The third section, "daily attitudes, and behaviors" aims to investigate the changes in people's lifestyle, such as changes in sleep and eating patterns as well as the usage of social media and the mode of occupation (physical presence in the workplace or teleworking) during the quarantine. Increased food intake and weight gain during the lockdown are reported (Di Renzo et al. 2020). The same situation is observed in sleep patterns, that is, a shift in the sleeping and waking up hours (Da Silva et al. 2020). During social distancing, the levels of social media use also increased (Wiederhold 2020), seeking medical information and support through these platforms (Saud et al. 2020). Finally, there is an important change in the working mode of the people. Teleworking entered and changed the course of people's everyday lives, ensuring wellbeing and productivity (ILO 2020). On the other hand, the pandemic caused an increase in unemployment and suspension from work (OECD 2020b).

The last section, "population's perceptions about COVID-19", concerns people's worries about getting infected by the virus (Mertens et al. 2020), perceptions about the 
preparedness of the government to face the pandemic (Koirala et al. 2020), and the role of the media and their response to the pandemic (Ferreira and Borges 2020).

It is necessary to clarify that the variables referring to the before COVID period concern January and February 2020, while the variables referring to the during COVID period concern the first lockdown period in Greece (Table 1).

Table 1. Sample sizes for alternative confidence level ( $\alpha$ ) and margin error (e).

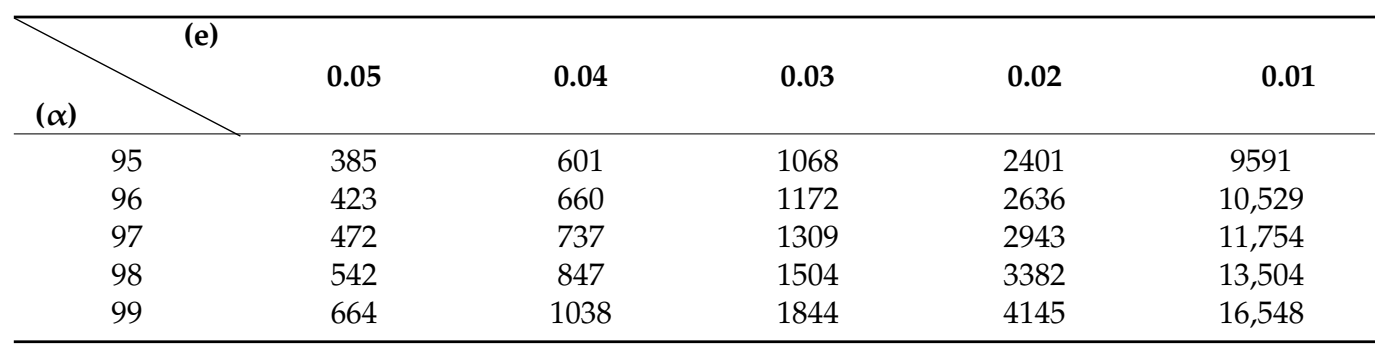

The data collection took place during the period 31 March 2020-23 April 2020, which concerns the first period of the lockdown, social distancing implementation, and house confinement. At that period, coronavirus restrictions on movement and social life were imposed, except for special permits as above-mentioned. Consequently, the Greek population was experiencing the effects of social distancing and isolation. Given both the critical health context and the institutional framework as regards population mobility, the survey, by force of circumstance, was conducted online. A web-based survey was designed using Google document forms. The survey was implemented through social media networks such as Facebook, Twitter and LinkedIn. In addition, having preliminarily established a list (at regional level-NUTS III) of professional organizations as well as main associations involved in cultural, sports and leisure activities, their assistance was required in order to encourage their members to participate in the survey and fulfill the online questionnaire. The objective was to ensure as far as possible the best spatial coverage of the country with individuals from different geographic areas and socioeconomic profiles. In any case, the participation was voluntary, while the individuals were initially informed about the context and the purpose of the research and the guaranty of the anonymity of responses. Participants also had the opportunity to either not answer questions they might not have wanted or to complete the entire questionnaire.

Additionally, a filter question concerning the age of the participants was applied, as the reference population retained for the survey concerned the permanent residents in Greece aged 15-65 years. The share of people 15-65 years among the total population is $63.6 \%$ (ELSTAT 2019). The young under 15 years as well as the elderly/seniors were, therefore, not included in the analysis. If children are obviously an especially sensitive group concerned by distancing measures, the implementation of self-administered questionnaires requires a specific and adapted approach-requiring among other parental consent-and that could not be followed in the context of the present research (Borgers et al. 2000; Fuchs 2009; Zill 2001). Official data also reveal that elderly (65+) in Greece are less likely to make use of the Internet than the average population (Eurostat 2017) while they have low overall digital skills (half of the EU's average) (Pouliopoulos et al. 2018). It was thus more than likely obvious that the number of responses covering the elderly would have been unrepresentative. In addition, to achieve a significant participation of the elderly in Greece, face-to-face interviews would have been conducted, though the confinement measures did not allow it. Should this not be the case, people's unprecedented fear of being infected through physical contact would deteriorate the scope of the present study.

Finally, 4305 questionnaires were collected, corresponding approximatively to a $99 \%$ confidence interval and a $2 \%$ margin of error (Table 1). Assuming that the proportion of the Greek population for which the feeling of social isolation has greatly increased is unknown, it is generally suggested to set the proportion at $50 \%$. This corresponds effectively to the worst scenario because for $\mathrm{p}=50 \%$, the variance of the binomial distribution $(=\mathrm{pq})$ is 
maximum, whatever the size of the sample. The size of the sample then depends on the choice concerning the confidence level $(\alpha)$ and the margin error (e) with:

$$
\text { sample size }=\frac{\mathrm{z}_{\alpha}^{2} \times \mathrm{p} \times \mathrm{q} \times \mathrm{e}^{2}}{\mathrm{e}^{2}+\left(\mathrm{z}_{\alpha}^{2} \times \mathrm{p} \times \mathrm{q} \times \frac{\mathrm{e}^{2}}{\mathrm{~N}}\right)} \approx \frac{\mathrm{z}_{\alpha}^{2} \times \mathrm{p} \times \mathrm{q} \times \mathrm{e}^{2}}{\mathrm{e}^{2}} \text { when population size } \mathrm{N} \text { very large }
$$

A total of 4.216 questionnaires were fully completed while 89 (2.1\%) presenting quite systematic missing data as regards the central core of the questionnaire were excluded, i.e., a completion rate of $97.8 \%$. This sample also covers all regions of Greece, urban and rural areas, remote areas (mountainous and Northern border areas) as well as most islands of the country: large islands such as Rhodes, Lesvos, Samos, Chios and smallest as Andros, Mikonos, Naxos, Paros, etc. As expected, the rural areas are underrepresented: around 17\% of the individuals while the residents in such areas represent in 2019, 31\% of the national population (Eurostat). Conversely, the representativeness of the islands is satisfactory with a survey's percent of $11.3 \%$ against $12.9 \%$ at the national level.

In order to detect and evaluate the factors that affected the social isolation feeling of the Greek population during the home confinement, a multivariate analysis was conducted. Specifically, through exploratory factor analysis, an attempt was made to reduce the volume of the 27 initial variables (Table 2) to a limited number of composite and more comprehensive indexes, with as little information loss as possible. The factors were extracted on the basis of principal component analysis method (PCA), and the rotation method chosen was Varimax with Kaiser normalization. The initial conditions for performing factor analysis are met; the number of observations greater than 1000 is considered as "ideal" (Comrey and Lee 1992) while the ratio of initial variables to the total observations is adequate (4216 observations, 27 variables) (Hair et al. 1995; Garson 2008).

Table 2. Variables involved in the analysis.

\begin{tabular}{|c|c|c|c|}
\hline Variable & Description & Type & Mean (SD) $/ \%$ \\
\hline AGE & Age & Scale & $36.8(12.04)$ \\
\hline MAR & Marital status & Nominal 1 = Single, $2=$ Married & $29.1 \%$ Single \\
\hline EDU & Educational level & $\begin{array}{c}\text { Nominal } \\
1=\text { Primary } / \text { elementary school } \\
2=\text { High school } \\
3=\text { Bachelor's degree } \\
4=\text { Master's degree } \\
5=\text { PhD }\end{array}$ & $\begin{array}{c}0.4 \% \\
3.3 \% \\
12.5 \% \\
29.6 \% \\
5.6 \%\end{array}$ \\
\hline A2 & Children residing in the house & Scale & $0.71(0.99)$ \\
\hline A5 & Employment status & $\begin{array}{c}\text { Nominal } \\
2=\text { on suspension/dismissal during COVID } \\
3=\text { Employed } \\
4=\text { Employer }\end{array}$ & $\begin{array}{l}28.1 \% \\
13.0 \% \\
41.7 \% \\
17.3 \%\end{array}$ \\
\hline A6 & Urbanity & $\begin{array}{l}1=\text { Urban areas } \\
2=\text { Rural areas }\end{array}$ & $\begin{array}{l}83.4 \% \\
16.6 \% \\
\end{array}$ \\
\hline A7 & Insularity & $\begin{array}{c}1=\text { Island } \\
2=\text { Mainland }\end{array}$ & $\begin{array}{l}11.3 \% \\
88.7 \%\end{array}$ \\
\hline B1 & Muscle pain & Ordinal Likert $1-5$ * & $2.40(1.24)$ \\
\hline B2 & Migraines/headaches & Ordinal Likert $1-5$ * & $2.39(1.21)$ \\
\hline B3 & Insomnia & Ordinal Likert 1-5 * & $2.89(1.40)$ \\
\hline B4 & Concentration difficulties & Ordinal Likert $1-5$ * & $2.62(1.30)$ \\
\hline B5 & Attention deficit disorder & Ordinal Likert $1-5$ * & $2.46(1.27)$ \\
\hline B6 & Anger & Ordinal Likert 1-5* & $2.84(1.32)$ \\
\hline B7 & Fatigue & Ordinal Likert $1-5$ * & $2.77(1.30)$ \\
\hline
\end{tabular}


Table 2. Cont.

\begin{tabular}{|c|c|c|c|}
\hline Variable & Description & Type & Mean (SD) $/ \%$ \\
\hline B8 & Irritability & Ordinal Likert 1-5* & $3.13(1.29)$ \\
\hline B10 & Sadness & Ordinal Likert $1-5$ * & $2.67(1.28)$ \\
\hline $\mathrm{C} 1$ & Time of going to sleep (before COVID) & Ordinal Likert $1-5^{* *}$ & $4.06(1.21)$ \\
\hline $\mathrm{C} 2$ & Time of going to sleep (during COVID) & Ordinal Likert $1-5^{* *}$ & $4.84(1.27)$ \\
\hline $\mathrm{C} 3$ & Time of waking up (before COVID) & Ordinal Likert $1-5^{* * *}$ & $3.71(1.25)$ \\
\hline $\mathrm{C} 4$ & Time of waking up (during COVID) & Ordinal Likert $1-5$ *** & $4.67(1.32)$ \\
\hline C11 & Use of social media (before COVID) & Ordinal Likert $1-5$ * & $2.62(1.18)$ \\
\hline C14 & Use of social media (during COVID) & Ordinal Likert $1-5$ * & $2.95(1.15)$ \\
\hline $\mathrm{C} 21$ & $\begin{array}{l}\text { Keep working with a physical presence in } \\
\text { the workplace }\end{array}$ & Ordinal Likert 1-5* & $2.00(0.70)$ \\
\hline $\mathrm{C} 22$ & Keep working by teleworking & Ordinal Likert $1-5$ * & $1.82(0.80)$ \\
\hline D5 & Worries about getting infected & Ordinal Likert $1-5$ * & $3.15(1.21)$ \\
\hline D8 & $\begin{array}{l}\text { There is no apparent reason to be afraid of } \\
\text { COVID }\end{array}$ & Ordinal Likert $1-5$ * & $2.26(1.21)$ \\
\hline D9 & Preparedness of the government & Ordinal Likert $1-5$ * & $3.18(1.32)$ \\
\hline D10 & $\begin{array}{l}\text { Satisfaction with the media's response to } \\
\text { COVID }\end{array}$ & Ordinal Likert $1-5$ * & $3.25(1.31)$ \\
\hline D15 & Concern about family health & Ordinal Likert $1-5$ * & $4.08(1.12)$ \\
\hline
\end{tabular}

$* 1=$ totally disagree $\ldots 5=$ totally agree. ${ }^{* *} 1=21: 00,2=22: 00,3=23: 00,4=24: 00,5=01: 00$ or later. ${ }^{* * *} 1=06: 00,2=07: 00,3=08: 00$, $4=09: 00,5=10: 00$ or later.

Finally, in order to examine possible differences in the assessment of the above factors depending on whether individuals live in urban or rural areas or in regions with relative geographical isolation (island environment), nonparametric tests were implemented. As well known, nonparametric tests do not require that the data be normally distributed. The implementation of Kolmogorov-Smirnov and Shapiro-Wilk tests confirmed that any one of the seven factors was normally distributed (Appendix A, Table A1). The question addressed here is the following: to what extent the place of residence and the relative geographical isolation can generate significant differences in the population's assessment of the impact of the factors highlighted through PCA?

\section{Results}

Of the 4216 participants $(\mathrm{M}$ age $=36.8, \mathrm{SD}=12.0), 1228$ were male $(\mathrm{M}$ age $=40.1$, $\mathrm{SD}=12.05)$ and 2988 were female $(\mathrm{M}$ age $=35.5, \mathrm{SD}=12.04)$. The gender distribution of the sample confirms that quite often, women are more willing to respond to social surveys than men (Bayart and Bonnel 2008, p. 55). More than one-third (35\%) of the entire sample reported moderate to a high feeling of social distancing, $20.3 \%$ of the sample reported moderate to extreme satisfaction from its life during confinement, and $36 \%$ of the sample reported moderate to extremely severe symptoms of sadness.

The implementation of PCA indicates seven principal components addressing the feeling of social isolation of the Greek population. The Kayser-Meyer-Olkin criterion justifies the suitability of data as they indicate high consistency $(\mathrm{KMO}=0.792)$ while each one of the 27 initial variables shows significant communality $(>0.4)$, justifying its contribution to the final model. The volume of the initial variables is reduced at $74 \%$ (27 initial variables shaped seven principal components), interpreting $63.2 \%$ of the total variability. The number of principal components was based on the criterion of eigenvalues $(\lambda>1)$. Finally, in terms of decreasing importance, psychosomatic disorders, employment situations, changes in sleep habits, socialization through the Internet, demographic status, health concerns, and trust in government and the media are the main components impacting the Greeks' social isolation feeling (Table 3). 
Table 3. Determinants of social isolation feeling in Greece during the lockdown.

\begin{tabular}{|c|c|c|c|c|c|c|c|c|}
\hline & $\mathrm{H}^{2(a)}$ & 1 & 2 & 3 & 4 & 5 & 6 & 7 \\
\hline B5 & 0.664 & 0.792 & & & & & & \\
\hline B4 & 0.665 & 0.792 & & & & & & \\
\hline B7 & 0.633 & 0.763 & & & & & & \\
\hline B10 & 0.543 & 0.731 & & & & & & \\
\hline B6 & 0.616 & 0.721 & & & & & & \\
\hline B8 & 0.581 & 0.720 & & & & & & \\
\hline B2 & 0.518 & 0.713 & & & & & & \\
\hline B3 & 0.508 & 0.674 & & & & & & \\
\hline B1 & 0.457 & 0.667 & & & & & & \\
\hline $\mathrm{C} 22$ & 0.729 & & 0.850 & & & & & \\
\hline A5 & 0.728 & & -0.822 & & & & & \\
\hline $\mathrm{C} 21$ & 0.666 & & 0.764 & & & & & \\
\hline EDU & 0.479 & & -0.587 & & & & & \\
\hline $\mathrm{C} 2$ & 0.724 & & & 0.837 & & & & \\
\hline $\mathrm{C} 4$ & 0.649 & & & 0.771 & & & & \\
\hline $\mathrm{C} 1$ & 0.588 & & & 0.755 & & & & \\
\hline $\mathrm{C} 3$ & 0.635 & & & 0.704 & & & & \\
\hline $\mathrm{C} 14$ & 0.866 & & & & 0.926 & & & \\
\hline C11 & 0.862 & & & & 0.922 & & & \\
\hline MAR & 0.737 & & & & & 0.831 & & \\
\hline A2 & 0.514 & & & & & 0.669 & & \\
\hline AGE & 0.633 & & & & & 0.612 & & \\
\hline D5 & 0.630 & & & & & & 0.772 & \\
\hline D15 & 0.590 & & & & & & 0.747 & \\
\hline D8 & 0.518 & & & & & & -0.605 & \\
\hline D9 & 0.704 & & & & & & & 0.825 \\
\hline D10 & 0.719 & & & & & & & 0.803 \\
\hline \multicolumn{2}{|c|}{$\%$ of total variance } & 20.4 & 12.9 & 7.6 & 7.0 & 6.3 & 4.7 & 4.3 \\
\hline
\end{tabular}

\subsection{First Component: Psychosomatic Disorders (20.4\% of Total Variance)}

The first component, which contributes to the highest percentage in the interpretation of social isolation feel, highlights the psychological aspect of the phenomenon. Psychosomatic feelings during social distancing measures with high correlation rates, namely muscle pain, migraines/headaches, insomnia, concentration difficulties, attention deficit disorder, anger, fatigue, irritability, and sadness, impact the composition of the first component.

\subsection{Second Component: Employment Situation (12.9\%)}

Variables reflecting the employment conditions of the population during the pandemic are merged in the composition of the second component. Taking for granted that the COVID crisis deteriorated the employment situation in Greece, the second component, therefore, reflects the significance of keep working at $12.9 \%$ of the total variability. The variables combined concern both the teleworking and the physical presence in the workplace in the outbreak of the pandemic and correlate positively. It is evident that there is an inverse relation to the population on suspension or the unemployed. The educational level, although low loading, is negatively correlated with the factor.

\subsection{Third Component: Changes in Sleep Patterns (7.6\%)}

The third component consists of four variables and reflects the changes in sleep habits before and during the lockdown measures. The loadings of these variables are positivesuggesting positive correlations among them. The shift in sleep time resulted in waking up 
later, disrupting the daily routine. This dimension indirectly captures the people's overall functioning, as sleep is critical for physical and mental health.

\subsection{Fourth Component: Socialization through the Internet (7.0\%)}

This component contains the variables that reflect the need for socializing during social distancing and home confinement. These variables have considerably high loadings and correlate with the factor positively. Despite the limited number of variables, this factor describes the choice of using social media through smartphones, tablets, and computers to contact friends and maintain a minimum level of social interaction.

\subsection{Fifth Component: Demographic Situation (6.3\%)}

A critical aspect of the sense of isolation in the pandemic involves the demographic profile of the Greek population. The fifth component refers to a factor that partly reflects the individuals' demographic situation. The variables comprising this component, namely marital status, age, and the number of children residing in a house, correlate positively. This component indirectly reflects the need for interaction with as few people as possible inside the house, avoiding the stain and tension the confinement provokes.

\subsection{Sixth Component: Health Concern (4.7\%)}

The sixth component reveals the worry and anxiety of the respondents about the possibility to infect with the virus themselves or their families. It consists of three variables with moderate factor loadings. The individuals are disturbed by the new reality and consider that there is a cause of concern followed by the risk of catching the coronavirus.

\subsection{Seventh Component: Trust in Government and the Media (4.3\%)}

The latter component has the least weight in the impact on social isolation feeling; however, as is evident by its high loadings, it is a classic reason affecting peoples' sense of safety. The initial variables that form the last component concern the peoples' perception of the government emergency preparedness for pandemic as well as the information on COVID-19. By trusting the government's response for tackling the pandemic, people refrain from feelings of confusion and stress.

To test the hypothesis of differences in the factors affecting social isolation between urban and rural residents, Mann-Whitney test was performed, highlighting significant differences ( $p$-value $<0.001)$ as regards three of the seven factors (Employment situation, changes in sleep patterns, and demographic status) and also, but in a less extent ( $p$-value $<10 \%$ ), Health concern (Table 4 ).

Examining more specifically the mean ranks, it appears that the impact of employment and demographic situation, as well as the health concern, is relatively more important for residents living in rural areas compared to urban residents, while sleep disturbances are more intense for urban residents than rural ones. The fact that the rural population gave a higher score in health concern can be explained in part by a relative lack of local health structures, especially hospitals that are located in the main regional city (the administrative center). No significant differences can be detected in terms of psychosomatic disorders, socialization through the Internet, and trust in government and media.

Regarding the population living in islands, significant differences are once again observed for three factors (Table 5). Demographic situation and employment situation present a higher score in island areas. The higher importance attributed to the employment situation in island areas can be explained by the fact that their main economic activity (tourism) was suddenly stopped, paralyzing the entire local economy. Conversely, sleep disorders seem to be more moderate in island areas compared to other regions. It is finally interesting to mention that, despite the relative geographical isolation, no significant differences can be observed as regards health concerns. It is true that at least the main islands of the country have health infrastructure (including hospitals), which is not the case for many inland rural areas. 
Table 4. Differences between urban and rural residents.

\begin{tabular}{cccccc}
\hline \multirow{2}{*}{ Factors } & \multicolumn{2}{c}{ Mean Rank } & \multirow{2}{*}{ Mann-Whitney U } & Z & \multirow{2}{*}{$\boldsymbol{p}$-Value } \\
\cline { 2 - 5 } & Urban Areas & Rural Areas & & -1.338 & 0.181 \\
Psychosomatic disorders & 2097.63 & 2030.53 & $1,165,352$ & -4.354 & 0.000 \\
Employment situation & 2050.30 & 2268.56 & $1,078,094$ & -2.497 & -0.398 \\
Changes in sleep patterns & 2107.27 & 1982.07 & $1,131,815$ & -2.572 & 0.013 \\
Socialization through Internet & 2083.19 & 2103.12 & $1,192,576$ & -1.713 & 0.010 \\
Demographic situation & 2065.11 & 2194.04 & $1,129,659$ & $1,154,506$ & -0.911 \\
Health concern & 2072.25 & 2158.14 & $1,177,730$ & 0.363 \\
Trust in government and media & 2094.07 & 2048.42 & & & \\
\hline
\end{tabular}

Table 5. Differences between inland areas and islands.

\begin{tabular}{|c|c|c|c|c|c|}
\hline \multirow{2}{*}{ Factors } & \multicolumn{2}{|c|}{ Mean Rank } & \multirow{2}{*}{ Mann-Whitney U } & \multirow{2}{*}{$\mathbf{Z}$} & \multirow{2}{*}{$p$-Value } \\
\hline & Inland Areas & Island & & & \\
\hline Psychosomatic disorders & 2084.13 & 2104.98 & 867,668 & -0.355 & 0.723 \\
\hline Employment situation & 2071.88 & 2200.55 & 822,368 & -2.190 & 0.029 \\
\hline Changes in sleep patterns & 2107.76 & 1920.64 & 797,806 & -3.184 & 0.001 \\
\hline Socialization through Internet & 2096.43 & 2009.07 & 839,723 & -1.487 & 0.137 \\
\hline Demographic situation & 2062.77 & 2271.67 & 788,654 & -3.555 & 0.000 \\
\hline Health concern & 2086.40 & 2087.24 & 876,073 & -0.014 & 0.989 \\
\hline Trust in government and media & 2082.86 & 2114.90 & 862,965 & -0.545 & 0.586 \\
\hline
\end{tabular}

\section{Conclusions}

Home confinement, the avoidance of social contacts and the adoption of hygiene and self-protection measures due to the spread of the coronavirus have inevitable psychological side effects in a great part of the population in Greece. Research suggests that quarantine and long-term isolation can lead to post-traumatic stress, anxiety, depression, but also to fatigue, widespread demoralization, and, eventually, public reaction (Brooks et al. 2020). These findings become stronger, realizing that social isolation and hunger leave about the same neuronal imprint on the brain (Tomova et al. 2020).

This paper is among the first general reviews on social isolation determinants in Greece, posed by COVID-19. After examining 4216 Greek people, the results indicate that a large range of factors has contributed to developing social isolation feeling among the Greek population. Among them, the psychosomatic disorders, as well as the employment situation, are obviously predominant. To a lesser extent, three other factors follow changes in sleep habits, socialization through the Internet, and demographic status. Finally, health concerns and trust in government and media have a relatively limited role-comparatively with the five above-mentioned factors-in determining the Greeks' social isolation feeling. These ominous changes impact the feeling of social isolation and, consequently, the wellbeing of the population.

As regards the factors that determined the social isolation feeling, insightful findings are reported on the differences between urban and rural residents, as well as inland and island ones. The impact of employment and demographic situation, as well as the health concern, is relatively more important for residents living in rural areas compared to urban residents, while sleep disturbances are more intense for urban residents than rural ones. Unequal "social-COVID" geographies are also observed in the Greek islands presenting a higher score in both demographic and employment situations. Conversely, sleep disorders seem to be more moderate in island areas compared to other regions. The relative geographical isolation of the islands, though, does not imply further health concerns compared to the inland regions. In line with the findings, the regions need to engage further with equity issues and sustainable development to support populations ${ }^{\prime}$ wellbeing during the pandemic (Chattu and Chami 2020). 
The present study highlighted the factors the determined the social isolation feeling of the Greek population during the lockdown period. Though, the short time period available to collect (two months), analyze and present data, as well as the changing nature of the pandemic, begs the question of whether these results are differentiated in the meantime.

Considering the second transmission wave of the virus, updated research data are urgently needed to support interventions and strategies for preventing further social isolation feeling. Multidisciplinary research is needed to evaluate interventions on preventing and/or addressing the social isolation feeling posed by COVID-19, as social cohesion with parallel physical distancing is the key to confront the pandemic (Gupta and Dhamija 2020).

Author Contributions: E.A. contributed to the design and implementation of the research, to the analysis of the results and to the writing of the manuscript. M.-N.D. contributed to the design and implementation of the research, to the analysis of the results and to the writing of the manuscript. All authors have read and agreed to the published version of the manuscript.

Funding: This research received no external funding.

Institutional Review Board Statement: Not applicable.

Informed Consent Statement: Not applicable.

Data Availability Statement: The data presented in this study are available on request from the corresponding author. The data are not publicly available due to confidentiality agreements with participants.

Conflicts of Interest: The authors declare no conflict of interest.

\section{Appendix A}

Table A1. Tests of normality for the seven factors extracted.

\begin{tabular}{ccccccc}
\hline \multirow{2}{*}{ Factors } & \multicolumn{3}{c}{ Kolmogorov-Smirnov $^{\mathbf{a}}$} & \multicolumn{2}{c}{ Shapiro-Wilk } \\
\cline { 2 - 6 } & Statistic & $\mathbf{d f}$ & $\boldsymbol{p}$-Value & Statistic & df & $p$-Value \\
\hline Psychosomatic disorders & 0.060 & 4172 & 0.000 & 0.977 & 4172 & 0.000 \\
Employment situation & 0.109 & 4172 & 0.000 & 0.927 & 4172 & 0.000 \\
Changes in sleep patterns & 0.053 & 4172 & 0.000 & 0.979 & 4172 & 0.000 \\
Socialization on the Internet & 0.101 & 4172 & 0.000 & 0.915 & 4172 & 0.000 \\
Demographic status & 0.107 & 4172 & 0.000 & 0.958 & 4172 & 0.000 \\
Health concern & 0.036 & 4172 & 0.000 & 0.989 & 4172 & 0.000 \\
Trust in government and media & 0.030 & 4172 & 0.000 & 0.990 & 4172 & 0.000 \\
\hline
\end{tabular}

${ }^{a}$ Lilliefors significance correction.

\section{References}

AAICJ. 1985. The Siracusa Principles on the Limitation and Derogation Provisions in the International Covenant on Civil and Political Rights. New York: AAICJ.

Ammar, Achraf, Khaled Trabelsi, Michael Brach, Hamdi Chtourou, Omar Boukhris, Liwa Masmoudi, Bassem Bouaziz, Ellen Bentlage, Daniella How, Mona Ahmed, and et al. 2020. Effects of Home Confinement on Mental Health and Lifestyle Behaviours during the COVID-19 Outbreak: Insight from the ‘ECLB-COVID19' Multi Countries Survey. medRxiv. [CrossRef]

Anastasiou, Evgenia, and Marie-Noelle Duquenne. 2020. Coronavirus in Society: The Geography of Social Distancing Measures in Greece. Demo News 41: 1-5. [CrossRef]

Anastasiou, Evgenia, and Stella Manika. 2020. Perceptions, Determinants and Residential Satisfaction from Urban Open Spaces. Open Journal of Social Sciences 8: 1-18. [CrossRef]

Armitage, Richard, and Laura B. Nellums. 2020. COVID-19 and the Consequences of Isolating the Elderly. The Lancet Public Health 5: e256. [CrossRef]

Barrett, Chris, Keith Bisset, Jonathan Leidig, Achla Marathe, and Madhav Marathe. 2011. Economic and Social Impact of Influenza Mitigation Strategies by Demographic Class. Epidemics 3: 19-31. [CrossRef] [PubMed]

Bayart, Caroline, and Patrick Bonnel. 2008. Enquête Web Auprès Des Non-Répondants à l'enquête Ménages Déplacements de Lyon 2005-2006. Lyon: Laboratoire d’Economie des Transports, Université Lyon Lumière 2. 
Berg-Weger, Marla, and Jonh Morley. 2020. Loneliness and Social Isolation in Older Adults during the COVID-19 Pandemic: Implications for Gerontological Social Work. Journal of Nutrition, Health and Aging 24: 456-58. [CrossRef] [PubMed]

Borgers, Natacha, Edith de Leeuw, and Joop Hox. 2000. Children as Respondents in Survey Research: Cognitive Development and Response Quality 1. Bulletin of Sociological Methodology/Bulletin de Méthodologie Sociologique 66: 60-75. [CrossRef]

Brooks, Samantha K., Rebecca K. Webster, Louise E. Smith, Lisa Woodland, Simon Wessely, Neil Greenberg, and Gideon James Rubin. 2020. The Psychological Impact of Quarantine and How to Reduce It: Rapid Review of the Evidence. The Lancet 395: 912-20. [CrossRef]

Chattu, Vijay Kumar, and Georgina Chami. 2020. Global Health Diplomacy amid the COVID-19 Pandemic: A Strategic Opportunity for Improving Health, Peace, and Well-Being in the CARICOM Region-A Systematic Review. Social Sciences 9: 88. [CrossRef]

Comrey, Andrew Lawrence, and Howard Lee. 1992. A First Course in Factor Analysis, 2nd ed. Hillsdale: Lawrence Erlbaum.

Da Silva, Flavia Rodrigues, Antonio Herbert Lancha Junior, Valdênio Martins Brant, Ingrid Ludimila Bastos Lôbo, Luciana Oquendo Pereira Lancha, Andressa Silva, and Marco Túlio de Mello. 2020. The Effects of COVID-19 Quarantine on Eating and Sleeping Behaviors. Nutrire 45: 1-4. [CrossRef]

Di Renzo, Laura, Paola Gualtieri, Francesca Pivari, Laura Soldati, Alda Attinà, Giulia Cinelli, Giulia Cinelli, Giovanna Caparello, Luigi Barrea, Francesco Scerbo, and et al. 2020. Eating Habits and Lifestyle Changes during COVID-19 Lockdown: An Italian Survey. Journal of Translational Medicine 18: 1-15. [CrossRef] [PubMed]

Douglas, Margaret, Srinivasa Vittal Katikireddi, Martin Taulbut, Martin McKee, and Gerry McCartney. 2020. Mitigating the Wider Health Effects of Covid-19 Pandemic Response. BMJ 369. [CrossRef]

ELSTAT. 2019. Press Release. Estimated Population (1.1.2019) and Migratory Flows (2018). Athens: Hellenic Statistical Authority.

Eurofound. 2020. Living, Working and COVID-19-First Findings-April 2020. Dublin: Eurofound.

European Union Agency for Fundamental Rights (FRA). 2020. Coronavirus COVID-19 Outbreak in the EU Fundamental Rights Implications. Luxembourg: Publications Office of the European Union.

Eurostat. 2017. People in the EU: Who Are We and How Do We Live? Luxembourg: European Union.

Ferreira, Gil Baptista, and Susana Borges. 2020. Media and Misinformation in Times of COVID-19: How People Informed Themselves in the Days Following the Portuguese Declaration of the State of Emergency. Journalism and Media 1: 108-21. [CrossRef]

Fuchs, Marek. 2009. The Reliability of Children's Survey Responses: The Impact of Cognitive Functioning on Respondent Behavior. In Proceedings of Statistics Canada Symposium 2008 Data Collection: Challenges, Achievements and New Directions. Edited by Marek Fuchs. Montreal: Canada's National Statistical Agency, pp. 522-31.

Galea, Sandro, Raina M. Merchant, and Nicole Lurie. 2020. The Mental Health Consequences of COVID-19 and Physical Distancing: The Need for Prevention and Early Intervention. JAMA Internal Medicine 180: 817-18. [CrossRef] [PubMed]

Garson, David. 2008. Factor Analysis: Statnotes. Raleigh: NorthCarolina State University.

Georgakopoulos, T. 2020. How Greeks Live in the Pandemic. Athens: Dianeosis Institute.

Gica, Sakir, Mehmet Kavakli, Yasemin Durduran, and Mehmet Ak. 2020. The Effect of COVID-19 Pandemic on Psychosomatic Complaints and Investigation of The Mediating Role of Intolerance to Uncertainty, Biological Rhythm Changes and Perceived COVID-19 Threat in This Relationship: A Web-Based Community Survey. Psychiatry and Clinical Psychopharmacology 30: 89-96. [CrossRef]

Gupta, Rajeev, and Rajinder Dhamija. 2020. Covid-19: Social Distancing or Social Isolation? BMJ 369: m2399. [CrossRef]

Gutik Valerievna, Tatiana, and Irina Anatolievna Gareeva. 2020. Factors Which Determine Population Behavior Strategies In The Sphere Of Health Protection (Sociological Analysis). Humanities E Social Sciences Reviews 8: 280-87. [CrossRef]

Hair, Joseph F., Rolph E. Anderson, Ronald L. Tatham, and William C. Black. 1995. Multivariate Data Analysis. Englewood Cliffs: Prentice-Hall.

ILO. 2020. Teleworking during the COVID-19 Pandemic and beyond A Practical Guide. Switzerland: International Labour Organization, Available online: www.ilo.org/publns (accessed on 15 November 2020).

Ismail, Leila Cheikh, Tareq M. Osaili, Maysm N. Mohamad, Amina Al Marzouqi, Amjad H. Jarrar, Dima O. Abu Jamous, Emmanuella Magriplis, Habiba I. Ali, Haleama Al Sabbah, Hayder Hasan, and et al. 2020. Eating Habits and Lifestyle during Covid-19 Lockdown in the United Arab Emirates: A Cross-Sectional Study. Nutrients 12: 3314. [CrossRef]

Koirala, Jyoti, Acharya Suman, Neupane Madhusudan, Phuyal Moti Ram, Rijal Nimananda, and Khanal Umesh. 2020. Government Preparedness and Response for 2020 Pandemic Disaster in Nepal: A Case Study of COVID-19. SSRN. [CrossRef]

KPMG. 2020. Barometer for Working Conditions during Covid-19. Athens: KPMG Organization.

Manika, Stella. 2020. Transforming Vacant Commercial Spaces: From Localized Hotspots of Urban Shrinkage to 'Smart' Co-Working Places. Open Journal of Social Sciences 8: 86-97. [CrossRef]

Mertens, Gaëtan, Lotte Gerritsen, Stefanie Duijndam, Elske Salemink, and Iris M. Engelhard. 2020. Fear of the Coronavirus (COVID-19): Predictors in an Online Study Conducted in March 2020. Journal of Anxiety Disorders 74. [CrossRef] [PubMed]

Nicola, Maria, Zaid Alsafi, Catrin Sohrabi, Ahmed Kerwan, Ahmed Al-Jabir, Christos Iosifidis, Maliha Agha, and Riaz Agha. 2020. The Socio-Economic Implications of the Coronavirus Pandemic (COVID-19): A Review. International Journal of Surgery 78: 185-93. [CrossRef] [PubMed]

NPHO. 2020. Daily Report of Epidemiological Surveillance of Infection by New Coronavirus (COVID-19), Data until 01 June 2020, Time 15:00. Athens: National Public Health Organization. 
O.J. 2020a. Official Journal 783B/10-03-2020. Imposition of the Measure of Temporary Ban on the Operation of Educational Institutions. Available online: https://www.in.gr/wp-content/uploads/2020/03/document-3.pdf (accessed on 1 November 2020).

O.J. 2020b. Official Journal B986/22-03-2020. Temporary Restriction of the Mobility of the Citizens in Order to Tackle the Risk of Spread of the Coronavirus COVID-19. Available online: http:/ / www.et.gr/idocs-nph/pdfimageSummaryviewer.html?args=sppFfdN7 IQP5_cc--m0e18iAcc4jHg5cfZAqqLVFOl28rzSZFxgk-WtPb3dFROTQkAYi3ORfmar8dCG08ptqqB8_VF_296K14kicnjz_3u5 MoFXpEKrZ6c77k1-A9Eyz7vqZ2xJ5_DZmaxFEWEXjkfE-hJkJxlJ38R3cRcvVlvM5wxNGZV4fbg (accessed on 1 November 2020).

O.J. 2020c. Oficcial Journal B915/17-3-2020. Imposition of the Measure of Temporary Ban on the Operation of Private Businesses. Available online: http://www.et.gr/idocs-nph/pdfimageSummaryviewer.html?args=sppFfdN7IQP5_cc--m0e18iAcc4jHg5 ceOnyQVhdpBS8rzSZFxgk-WtPb3dFROTQkAYi3ORfmao439JLDXm-TyWJgdNHAvT44kicnjz_3u5MoFXpEKrZ6c77k1-A9 Eyz7vqZ2xJ5_Da_RK0cQzMa028wCmWFwJGsjT3u-efZo8c85WUHcEcRuw (accessed on 1 November 2020).

OECD. 2020a. Regulatory Quality and COVID-19: Managing the Risks and Supporting the Recovery. Paris: OECD.

OECD. 2020b. The Impact of the COVID-19 Pandemic on Jobs and Incomes in G20 Economies. Paris: OECD.

Panagiotopoulos, Takis, and Dimitris Papamichail. 2020. Coronavirus-19 (COVID-19) Disease Mortality Trends. Comparisons between Greece and Other European Countries. Athens: University of West Attica.

Pouliopoulos, Theofilos, Maria Moschou, Fausto Amico, Maria Jose Freitas, Madalina Ostafe, and Dalia Puente. 2018. Development of Digital Skills Building Framework through Social Media for Low-Skilled/Low-Qualified Unemployed Persons over 45 KMOP Discussion Paper 109. Thessaloniki: Social Action and Innovation Centre.

Qiu, Jianyin, Bin Shen, Min Zhao, Zhen Wang, Bin Xie, and Yifeng Xu. 2020. A Nationwide Survey of Psychological Distress among Chinese People in the COVID-19 Epidemic: Implications and Policy Recommendations. General Psychiatry 33: 100213. [CrossRef] [PubMed]

Ragazou, Konstantina. 2020. The Impact of Telecommuting on Sustainability in the Context of Covid 19. Paper presented at 27th APDR Congress: Sustainable Management of the Sea for Sustainable Regional Development, Angra do Heroísmo, Portugal, September 10-11.

Saud, Muhammad, Musta'in Mashud, and Rachmah Ida. 2020. Usage of Social Media during the Pandemic: Seeking Support and Awareness about COVID-19 through Social Media Platforms. Journal of Public Affairs 20: e02417. [CrossRef]

Stansfeld, S. A. 2006. Social Support and Social Cohesion. In Social Determinants of Health, 2nd ed. Edited by Michael Marmot and Wilkinson Richard. Oxford: Oxford University Press, pp. 148-71.

Suárez Fernández, G. 2011. Social impact of epidemic or pandemic infectious contagion. Anales de la Real Academia Nacional de Medicina 128: 245-63. [CrossRef] [PubMed]

Tomaka, Joe, Sharon Thompson, and Rebecca Palacios. 2006. The Relation of Social Isolation, Loneliness, and Social Support to Disease Outcomes among the Elderly. Journal of Aging and Health 18: 359-84. [CrossRef]

Tomova, Livia, Kimberly Wang, Todd Thompson, Gillian Matthews, Atsushi Takahashi, Kay Tye, and Rebecca Saxe. 2020. The Need to Connect: Acute Social Isolation Causes Neural Craving Responses Similar to Hunger. bioRxiv. [CrossRef]

UK YOUTH. 2020. The Impact of COVID-19 on Young People \& the Youth Sector. London: UK Youth London Office.

UN. 2020. Shared Responsibility, Global Solidarity. New York: The United Nations Sustainable Development Group.

UN WOMEN. 2020. COVID-19: Gendered Impacts of the Pandemic in Palestine and Implications for Policy and Programming Findings of a Rapid Gender Analysis of COVID-19 in Palestine. Jerusalem: UN Women Palestine Office.

UNDP. 2020. COVID-19 and Human Development: Assessing the Crisis, Envisioning the Recovery. New York: UNDP.

Wang, Guanghai, Yunting Zhang, Jin Zhao, Jun Zhang, and Fan Jiang. 2020. Mitigate the Effects of Home Confinement on Children during the COVID-19 Outbreak. The Lancet 395: 945-47. [CrossRef]

Wardani, Laila Meiliyandrie Indah, and Muhamad Syafiq Anwar. 2019. The Role of Quality of Work Life as Mediator: Psychological Capital and Work Engagement. Humanities and Social Sciences Reviews 7: 447-63. [CrossRef]

Wiederhold, Brenda K. 2020. Social Media Use During Social Distancing. Cyberpsychology, Behavior, and Social Networking 23: 275-76. [CrossRef]

Wielgus, Benita, Witold Urban, Aleksandra Patriak, and Łukasz Cichocki. 2020. Examining the Associations between Psychological Flexibility, Mindfulness, Psychosomatic Functioning, and Anxiety during the Covid-19 Pandemic: A Path Analysis. International Journal of Environmental Research and Public Health 17: 8764. [CrossRef] [PubMed]

Zill, N. 2001. Advantages and Limitations of Using Children and Adolescents as Survey Respondents. In Seventh Conference on Health Survey Research Methods. Edited by Cynamon Marcie and Richard Kulka. Hyattsville: Department of Health and Human Services. 